\title{
Surgical Outcomes in Syndromic Tetralogy of Fallot: A Systematic Review and Evidence Quality Assessment
}

\author{
Dimitrios I. Athanasiadis ${ }^{1,2} \cdot K^{\prime}$ onstantinos S. Mylonas ${ }^{1,3,4}$ (1) Karampet Kasparian $^{1,5} \cdot$ Ioannis A. Ziogas $^{1,5}$. \\ Dimitra Vlachopoulou ${ }^{5}$. Panagiotis G. Sfyridis ${ }^{3}$. Dimitrios Schizas ${ }^{6}$. Eleftherios Spartalis $^{4} \cdot$ Nikolaos Nikiteas $^{4}$. \\ Pouya Hemmati ${ }^{7} \cdot$ Afksendiyos Kalangos $^{3} \cdot$ Dimitrios V. Avgerinos $^{8}$
}

Received: 5 May 2019 / Accepted: 11 June 2019 / Published online: 18 June 2019

○) Springer Science+Business Media, LLC, part of Springer Nature 2019

\begin{abstract}
Tetralogy of Fallot (ToF) is one of the most common cyanotic congenital heart defects. We sought to summarize all available data regarding the epidemiology and perioperative outcomes of syndromic ToF patients. A PRISMA-compliant systematic literature review of PubMed and Cochrane Library was performed. Twelve original studies were included. The incidence of syndromic ToF was $15.3 \%(n=549 / 3597)$. The most prevalent genetic syndromes were 22q11.2 deletion (47.8\%; $95 \%$ CI 43.4-52.2) and trisomy $21(41.9 \%$; 95\% CI 37.7-46.3). Complete surgical repair was performed in $75.2 \%$ of the patients $(n=161 / 214$; 95\% CI 69.0-80.1) and staged repair in 24.8\% ( $n=53 / 214 ; 95$ CI 19.4-30.9). Relief of RVOT obstruction was performed with transannular patch in $64.7 \%(n=79 / 122$; 95\% CI 55.9-72.7) of the patients, pulmonary valve-sparing technique in $17.2 \%(n=21 / 122$; 95\% CI 11.5-24.9), and RV-PA conduit in $18.0 \%(n=22 / 122$; 95\% CI 12.1-25.9). Pleural effusions were the most common postoperative complications $(n=28 / 549 ; 5.1 \%$; 95\% CI 3.5-7.3). Reoperations were performed in $4.4 \%(n=24 / 549 ; 95 \%$ CI $2.9-6.4)$ of the patients. All-cause mortality rate was $9.8 \%(n=51 / 521 ; 95 \%$ CI 7.5-12.7). Genetic syndromes are seen in approximately $15 \%$ of ToF patients. Long-term survival exceeds $90 \%$, suggesting that surgical management should be dictated by anatomy regardless of genetics.
\end{abstract}

Keywords Tetralogy of Fallot $\cdot$ TOF $\cdot$ Cardiac surgery $\cdot$ Gene mutation $\cdot$ Genetics

Dimitrios I. Athanasiadis and Konstantinos S. Mylonas contributed equally to this work and share first authorship.

Electronic supplementary material The online version of this article (https://doi.org/10.1007/s00246-019-02133-z) contains supplementary material, which is available to authorized users.

Konstantinos S. Mylonas

ksmylonas@gmail.com

1 Pediatric Cardiac Surgery and Pediatric Cardiology Working Group, Society of Junior Doctors, Athens, Greece

2 Department of Surgery, Indiana University School of Medicine, Indianapolis, IN, USA

3 Department of Pediatric Cardiac Surgery, Mitera Children'S Hospital, Athens, Greece

4 Laboratory of Experimental Surgery and Surgical Research, School of Medicine, National and Kapodistrian University of Athens, Athens, Greece

\section{Introduction}

Tetralogy of Fallot (ToF) has an incidence of one in 3500 live births and constitutes one of the most common cyanotic congenital heart defects [1]. Classically, ToF is comprised of four components: ventricular septal defect (VSD), obstruction of the right ventricular outflow tract (RVOT), override of the aorta, and right ventricular hypertrophy. A significant

5 School of Medicine, Aristotle University of Thessaloniki, Thessaloniki, Greece

$6 \quad$ 1st Department of Surgery, Laikon University General Hospital, School of Medicine, National and Kapodistrian University of Athens, Athens, Greece

7 Department of Surgery, Mayo Clinic, Rochester, MN, USA

8 Department of Cardiothoracic Surgery, Weill Cornell Medicine, New York Presbyterian Hospital, New York City, NY, USA 
number of anatomical variants have been described, most commonly regarding malformations of the RVOT, such as hypertrophied subvalvar muscle, pulmonary annular hypoplasia, pulmonary valve stenosis, supravalvar pulmonary stenosis, and/or branch pulmonary artery (PA) stenosis [2].

Several chromosomal and genetic syndromes have been associated with ToF [3]. DiGeorge syndrome and other disorders within the 22q11.2 deletion spectrum are the genetic aberrations most commonly seen with ToF. Patients with trisomy 21, VACTERL syndrome, and trisomy 18 can also manifest ToF phenotypes. Syndromic patients tend to present with different cardiac anatomy and extracardiac features, which may impact their prognosis [4]. The purpose of this study was to systematically review and summarize all available data regarding the epidemiology and perioperative outcomes of syndromic ToF patients.

\section{Materials and Methods}

\section{Search Strategy}

This systematic review was conducted in accordance with the Preferred Reporting Items for Systematic Reviews and Meta-Analyses (PRISMA) guidelines (Online Resource 1) and in line with the protocol agreed by all authors. Eligible studies were identified through search of the PubMed bibliographical database and the Cochrane Library (end-of-search date: April 7th, 2018). The literature search was executed by two independent investigators (DIA and KK) using the following algorithm: tetralogy of Fallot AND (gene OR mutation OR variant $\mathrm{OR}$ genetics OR genome OR pathway).

Original clinical studies, published in English, reporting on demographics, clinical manifestations, diagnostic interventions, and postoperative outcomes of syndromic patients undergoing surgical repair of ToF were considered eligible for the present systematic review. The reference lists of systematically reviewed articles were hand-searched for potentially eligible, missed studies using snowball methodology.

Excluded studies were (1) papers published in a language other than English, (2) studies irrelevant to syndromic ToF, (3) in vitro studies, (4) animal studies, (5) reviews and metaanalyses, (6) letters to the editor, comments, errata, and (7) abstracts. Any disagreements were resolved by consensus with another author (KSM). No sample size restriction was applied when screening eligible studies.

\section{Data Extraction and Tabulation}

A standardized, pre-piloted form was used to extract and tabulate data from the included studies for evidence synthesis and assessment of study quality. Two reviewers (DIA and KK) extracted the data independently and any discrepancies were identified and resolved through quality control discussions with another author (KSM) whenever necessary. The following data were extracted for each eligible study: study characteristics (first author, year of publication, study design, number of patients), demographics (sex, age, race, weight), genetic data, extracardiac malformations (craniofacial, ocular, ear, nose, mouth, palate, respiratory, abdominal, renal, genital, skeletal, extremity), pulmonary valve status (stenosis, atresia, absent), PA stenosis, PA hypoplasia, aortic dilatation, valve regurgitation, right aortic arch, aberrant right subclavian artery, major aortopulmonary collateral arteries (MAPCA), aortic override more than 50\%, patent ductus arteriosus (PDA), discontinuous PA, multiple ventricular septal defects (VSDs), anomalous coronary artery pattern, anomalous systemic venous connection, choanal septal hypoplasia, surgical approach, operative data, hospitalization (length of stay, length of stay in intensive care unit, mechanical ventilation duration), complications, mortality, and cause of death.

\section{Statistical Analysis}

Categorical variables were summarized as frequencies and percentages accompanied by $95 \%$ confidence intervals $(95 \%$ $\mathrm{CI}$ ), while continuous variables were summarized as means and standard deviations (SDs). Data on outcomes of interest were tabulated and analyzed cumulatively. All relative rates were estimated based on available data for each variable of interest. Data analyses were performed in R 3.3.2 (R Core Team, Vienna, Austria).

\section{Assessment of Study Quality}

The quality of included studies was evaluated using the Newcastle-Ottawa Quality scale (NOS); [5] with a score of at least 6 indicating high quality. In the item assessing whether the follow-up period was long enough for outcomes to occur, the cut-off value was a priori set at 12 postoperative months, whereas regarding the item about the adequacy of follow-up, a 90\% rate was also a priori adopted. Two reviewers (DIA and KK) working independently rated the studies, and final decision was reached by consensus with another author (KSM).

\section{Results}

\section{Article Selection}

The initial literature search yielded 968 potentially relevant records. After screening titles and abstracts, 287 studies were retrieved for full-text evaluation. Ultimately, 12 studies [3, 4, 6-15] satisfied the predetermined search 
criteria and were included in this systematic review (Fig. 1). Four studies were conducted in the United States $[6,8,11,13]$, two in Canada $[9,14]$, four in Europe [3, 4, 7, 12], one in Latin America [15], and one in Asia [10].

\section{Quality of Evidence Assessment}

The mean NOS score for the 12 cohort studies that were included in the present systematic review was 5.7 (SD: 1.5) (high quality: six studies; fair quality: six studies). Detailed modified NOS quality assessment for included comparative studies is provided in Online Resource 2.
PIRIS M

\section{PRISMA 2009 Flow Diagram}

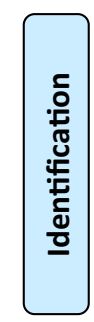

Records identified through PubMed database search $(n=963)$
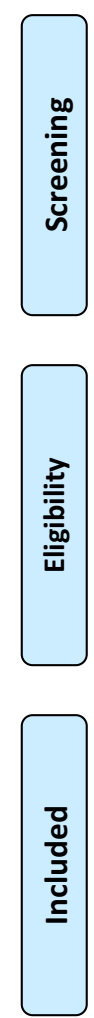

\section{Studies retrieved from} reference lists $(n=2)$

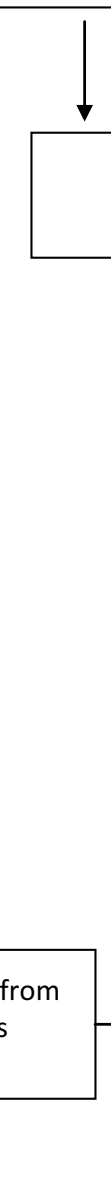

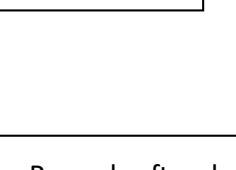

Records after duplicates removed $(n=968)$
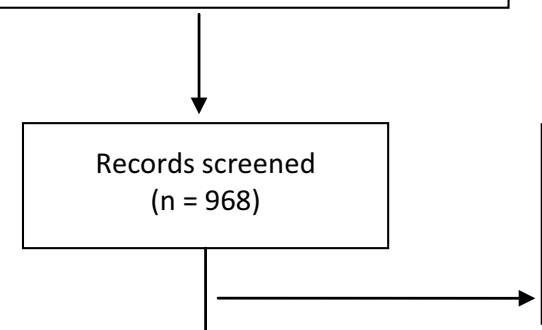

Records excluded after title abstract and screening ( $n=605)$

Additional records identified through Cochrane Library database search $(n=10)$

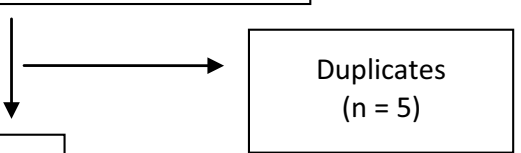

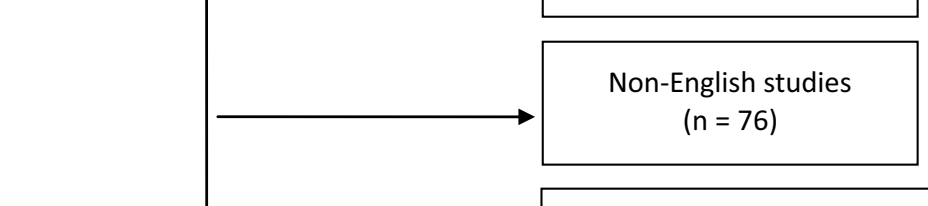

Full-text articles excluded

$$
\text { ( } n=279) \text { : }
$$

Non-surgical procedures: ( $\mathrm{n}=205)$

$$
\text { ( } n=58 \text { ) }
$$

Reviews

$$
(n=6)
$$

No full text available:

$$
(n=6)
$$

Studies included in qualitative synthesis $(n=12)$

Case Reports

$$
(n=2)
$$

Letter to the editor

$$
(n=1)
$$

Population overlap:

$$
(n=1)
$$

Fig. 1 PRISMA search flow chart 


\section{Patient Characteristics}

Systematically reviewed studies recruited a total of 3597 patients with ToF. The incidence of syndromic ToF was $15.3 \%(n=549 / 3597)$. The male-to-female ratio was 1.5:1 (201 males, 134 females, 214 unreported) and mean patient age at the time of surgery was $7.7 \pm 4.7$ months $[3,7,8,13]$. Neonates accounted for 3.6\% ( $n=20 / 459 ; 95 \%$ CI 2.8-6.7) of syndromic patients for whom age data were available. Mean weight at the time of surgery was $5.8 \pm 1.6 \mathrm{~kg}[8$, 13]. Clinical manifestations were reported in 55 syndromic patients. Cardiac and extracardiac malformations are summarized in Online Resource 3 and 4, respectively.

\section{Genetics}

Out of 549 patients with genetic syndromes, the specific genetic malformation was stated in $90.7 \%$ ( $n=498 / 549$; 95\% CI 87.9-92.9), while in 9.3\% of patients the genetic malformation was not reported. 22q11.2 deletion was found in 47.8\% ( $n=238 / 498$; 95\% CI 43.4-52.2), and Trisomy 21 in $41.9 \%$ ( $n=209 / 498,95 \%$ CI $37.7-46.3)$ of the patients. VACTERL association was described in $2.6 \%(n=13 / 498$; 95\% CI 1.3-4.1) of syndromic cases. A more detailed overview of genes associated with ToF is provided in Table 1.

\section{Perioperative Management}

Details on surgical approach were available in $46.6 \%$ $(n=214 / 459)$ of syndromic ToF cases $[3,6,7,10,11,13]$. Complete surgical repair was performed in $75.2 \%$ of the patients ( $n=161 / 214 ; 95 \%$ CI $69.0-80.1)$ and staged repair in $24.8 \%$ ( $n=53 / 214$; 95 CI 19.4-30.9). Details on palliation were available for eight patients: one central shunt, four Blalock-Taussig shunts (BT shunts), and three catheter-based balloon dilations. VSDs were repaired with patches. Relief of RVOT obstruction was performed with transannular patch in $64.7 \%(n=79 / 122 ; 95 \%$ CI 55.9-72.7) of the patients, while

Table 1 Genetic data of patients with syndromic Tetralogy of Fallot

\begin{tabular}{llc}
\hline Genetic data $\%(n)$ & Frequency & $95 \%$ CI \\
\hline 22q11.2 deletion & $47.8(238 / 498)$ & $43.4-52.2$ \\
Trisomy 21 & $41.9(209 / 498)$ & $37.7-46.3$ \\
VACTERL syndrome & $2.6(13 / 498)$ & $1.5-4.5$ \\
CHARGE syndrome & $0.4(2 / 498)$ & $<0.01-1.2$ \\
Trisomy 18 & $0.8(4 / 498)$ & $0.2-2.1$ \\
Trisomy 13 & $0.2(1 / 498)$ & $<0.01-1.5$ \\
Holt-Oram syndrome & $0.2(1 / 498)$ & $<0.01-1.5$ \\
49XXXXY & $0.2(1 / 498)$ & $<0.01-1.5$ \\
47, XX, + 14/46, XX & $0.2(1 / 498)$ & $<0.01-1.5$ \\
Fibrillin-1 mutations & $5.6(28 / 498)$ & $3.9-8.0$ \\
\hline
\end{tabular}

in $17.2 \%$ ( $n=21 / 122$; 95\% CI 11.5-24.9) a pulmonary valvesparing technique was used. Furthermore, a RV-PA conduit was created in $18.0 \%(n=22 / 122 ; 95 \%$ CI 12.1-25.9). Mean lengths of intensive care unit stay and hospitalization were $6.9 \pm 4.9$ days and $9.9 \pm 6.1$ days, respectively $[6-8,13]$. Moreover, patients requiring mechanical ventilation stayed on the ventilator for a mean of $45.5 \pm 72.3 \mathrm{~h}[6,7,13]$. Mean cardiopulmonary bypass time was $105.6 \pm 33.5 \mathrm{~min}[8,13]$.

\section{Postoperative Complications and Reoperations}

Postoperative morbidity was described in 5 studies $(n=318)$ [3, 7, 8, 12, 13]. A total of 102 complications were reported. The most frequent complications were pleural effusions $(5.1 \%, n=28 / 549 ; 95 \%$ CI $3.5-7.3)$, mostly chylothorax $(n=23$ of 28). Infections requiring antibiotics developed in $4.7 \%$ of the patients ( $n=26 / 549 ; 95 \%$ CI 3.2-6.9). Specifically, half were mild infections, including six surgical site infections and seven cases of pneumonia $(n=13 / 549$; 95\% CI 1.3-4.1). Sepsis was recorded in $2.4 \%$ of our cohort ( $n=13 / 549 ; 95 \%$ CI 1.3-4.1). Reoperations and cardiac catheterizations were performed in $4.4 \%(n=24 / 549 ; 95 \%$ CI 2.9-6.4) and 2.5\% ( $n=14 / 549$; 95\% CI 1.5-4.3) of the patients, respectively. Prolonged ventilation for over $48 \mathrm{~h}$ was needed in $2.2 \%$ of the patients $(n=12 / 549 ; 95 \% \mathrm{CI}$ $1.2-3.8)$. Only $1.1 \%$ of the patients experienced arrhythmias ( $n=6 / 549 ; 95 \%$ CI 0.4-2.4), of which four were junctional tachycardias, one third-degree atrioventricular block, and one unspecified. Postoperative complications are summarized in Table 2.

\section{Long-Term Outcomes}

Survival data were available for 521 (94.8\%) patients with syndromic ToF. Specifically, $90.2 \%$ of the patients survived $(n=470 / 521 ; 95 \%$ CI 87.3-92.5) and all-cause mortality was 9.8\% ( $n=51 / 521 ; 95 \%$ CI 7.5-12.7). The timeline and cause of death was described in 16 out of 51 fatalities (Table 3). Of note, four patients died in hospital, but the cause of the death was not further defined. Most common cause of in-hospital and out-of-hospital death were sepsis $(n=5 / 16 ; 31.2 \%, 95 \%$ CI 13.91-55.85) and pulmonary overcirculation $(n=2 / 16$; $12.5 \%, 95 \%$ CI 5.8-43.8), respectively.

\section{Discussion}

In the present systematic review, we analyzed the clinical and pathological features and surgical outcomes of patients with syndromic Tetralogy of Fallot. Using published literature, we estimated the incidence of syndromic ToF at approximately $15 \%$. Our analysis validates prior work showing 22q11.2 deletion (47.8\%) and Down's syndrome (41.9\%) 
Table 2 Postoperative complications in patients with syndromic Tetralogy of Fallot

\begin{tabular}{llc}
\hline Postoperative complications \% $(n)$ & Frequency & $95 \%$ CI \\
\hline Cardiac complications & & \\
Inotropic support $>72 \mathrm{~h}$ & $1.4(8 / 549)$ & $0.7-2.9$ \\
Arrhythmias & $1.1(6 / 549)$ & $0.4-2.4$ \\
Cardiac arrest & $1.1(6 / 549)$ & $0.4-2.4$ \\
Pericardial effusions & $0.2(1 / 549)$ & $<0.01-1.1$ \\
Pulmonary events & & \\
Pleural effusions & $5.1(28 / 549)$ & $3.5-7.3$ \\
Prolonged ventilation & $2.2(12 / 549)$ & $1.2-3.8$ \\
Respiratory failure & $0.5(3 / 549)$ & $0.1-1.7$ \\
Laryngeal stridor & $0.7(4 / 318)$ & $0.2-1.9$ \\
Infections & & \\
Mild & $2.4(13 / 549)$ & $1.3-4.1$ \\
Sepsis & $2.4(13 / 549)$ & $1.3-4.1$ \\
Neurological complications & $0.2(1 / 549)$ & $<0.01-1.1$ \\
Hypocalcemia & $1.3(7 / 549)$ & $0.6-2.7$ \\
\hline
\end{tabular}

to be the most common genetic abnormalities associated with ToF. We found that syndromic ToF is frequently associated with aortic dilatation (92.9\%) and MAPCAs (61.5\%) and describe in detail other cardiac pathologies that can be found in this group of patients. Importantly, our findings suggest that hypoplastic pulmonary arteries (22.3\%) may be more prevalent in syndromic compared to non-syndromic ToF (approximately 10\%) [3, 16].

It is important to emphasize that cardiac phenotype does differ based on underlying genetic profiles. Malformations of the aortic arch are extremely prevalent in $\mathrm{ToF} / 22 \mathrm{q} 11.2$ deletion. The incidence of MAPCAs seems to be particularly high $(91.0 \%)$ in this population. Right $(70.0 \%)$ and high (43.0\%) aortic arch as well as aberrant right or left subclavian artery $(35.0 \%)$ are also quite common in 22q11.2 deletion [17-19]. Higher frequency of isolated left PA, subaortic VSDs, and persistent left superior vena cava have also been reported in patients within the 22q11.2 deletion spectrum. The presence of atrioventricular septal defect (AVSD) is more often correlated with Down syndrome and typically makes 22q11.2 deletion less likely. Large genotype-phenotype studies have shown that ToF in the setting of Down syndrome is coupled with AVSDs in $25 \%$ of the cases [20-22]. Patients with ToF and mutations in exons 24-28 of the fibrillin-1 (FBN1) gene usually have aortic dilation [10]. In our systematic review, $92.8 \%$ of patients with FBN1 gene mutations had aortic dilatation and 28.5\% had aortic regurgitation. Additionally, among patients with FBN1 mutations, $85.7 \%$ had aortic override more than 50\%, $67.8 \%$ had MAPCAs, and $46.4 \%$ had right aortic arches. In CHARGE association, the prevalence of ToF is around $30 \%$ and cardiac pathology typically includes concomitant conotruncal abnormalities [20].

Surgical intervention is usually performed in the first year of life, with the majority of repairs performed electively before age 6 months. If the RVOT obstruction is not critical, intracardiac repair is typically deferred until after the neonatal period not only to allow pulmonary vascular resistance to drop but also to give time to the infant to gain weight [23]. Neonatal surgical intervention may be needed in the setting of severe RVOT obstruction with or without ductal dependency [24]. Primary intracardiac repair is generally attempted in these patients [25]. Palliative shunts, most frequently BT shunts, are performed when primary surgical repair is not an option (e.g., prematurity, medically refractory tet spells, coronary abnormalities, and hypoplastic PAs) $[26,27]$. According to our analysis $[3,6,7,10,13]$, nearly $25 \%$ of syndromic ToF patients underwent a staged repair, which is more than two times higher compared to the rate of staged repairs in non-syndromic ToF (approximately 10\%) [3]. This phenomenon may be at least partly attributed to the very high incidence of hypoplastic pulmonary arteries seen in syndromic patients.

Complete repair includes enlargement of the RVOT and patch closure of the VSD [22]. Most syndromic patients
Table 3 All-cause mortality in patients with syndromic Tetralogy of Fallot

\begin{tabular}{llrr}
\hline Mortality $\%(n)$ & Timeline & Frequency & 95\% CI \\
\hline In-hospital & & & \\
$\quad$ Sepsis & $<30$ days & $31.2(5 / 16)$ & $13.9-55.8$ \\
Right ventricular failure & $<30$ days & $18.7(3 / 16)$ & $5.8-43.8$ \\
Perioperative cardiac cause & Perioperative & $12.5(2 / 16)$ & $2.2-37.3$ \\
$\quad$ Multiorgan failure & 3 weeks after complete repair & $6.2(1 / 16)$ & $<0.01-30.3$ \\
Out-of-hospital & & & \\
Pulmonary overcirculation & $<30$ days & $12.5(2 / 16)$ & $5.8-43.8$ \\
$\quad$ Respiratory failure & 7 months after complete repair & $6.2(1 / 16)$ & $<0.01-30.3$ \\
$\quad$ Hepatic failure & 31 days after staged repair & $6.2(1 / 16)$ & $<0.01-30.3$ \\
Not specified & & & $<0.01-30.3$ \\
$\quad$ Sudden cardiac death & Unknown & $6.2(1 / 16)$ & \\
\hline
\end{tabular}


(64.7\%) seem to undergo RVOT enlargement through resection of infundibular and sub-infundibular muscle bundles followed by placement of a transannular patch to create unobstructed flow from the RV into the PAs [28, 29]. Although the transatrial approach carries a lower risk for late ventricular arrhythmias compared to ventriculotomy, two large population-based analyses demonstrated that ventriculotomy with transannular patch repair remains the most common strategy for repair of ToF [21, 30].

Nevertheless, techniques that help maintain pulmonary valve competence are increasingly gaining traction. In our systematic review, a "valve-sparing approach" [3, 13] was performed in $17.2 \%$ of syndromic ToF patients. However, there is no definite consensus on the size of the pulmonary annulus and the acceptable degree of residual RVOT obstruction that is amenable to a valve-sparing approach [31, 32]. Valved conduits from the RV to the distal main PA were placed in $18.0 \%$ of syndromic ToF patients [3, 13]. Although stenosis and/or regurgitation of the conduit prosthetic valve and conduit stenosis can occur, none of the eligible studies reported any of these complications [33, 34].

In our analysis, the most frequent complications were pleural effusions and infections requiring antibiotics. Of note, large series from Europe have shown that the complication rate of syndromic ToF patients $(47.1 \%)$ is significantly higher than those without genetic malformations (17.4\%). For this reason, longer ICU stay seems to be required in syndromic patients postoperatively (7.4 vs 2.9 days) [3]. No ventricular dysrhythmias or need for implantable cardioverter-defibrillator was reported. All-cause mortality for patients with syndromic ToF was 9.8\% and the most common cause of death was in-hospital sepsis. Reports from Europe suggest that genetic defects, other than 22q11.2 deletion and Down syndrome, may negatively impact long-term outcomes of ToF [3]. PA hypoplasia and surgical repair or palliation of extracardiac lesions seem to be independent risk factors for mortality in syndromic patients, possibly due to secondary changes in pulmonary compliance and pulmonary mechanics, as well as an increased incidence of gramnegative infections.

Freedom from reintervention in syndromic ToF has been shown to be significantly lower compared with nonsyndromic patients [3]. Residual RVOT obstruction and recurrent VSDs seem to be the dominant indication for redo operations or interventional procedures in the syndromic subgroup. Central PA hypoplasia and more frequent use of palliative procedures can account for a higher incidence of recurrent RVOT obstruction or branch PA stenosis after complete repair of cardiac lesions in syndromic ToF. Recurrent VSDs occur three times more frequently in TOF patients with genetic disorders [3]. Lastly, syndromic patients undergoing ToF repair may have poorer neurologic outcomes in the long run; presence of 22q11.2 deletion and APOE $\varepsilon 2$ allele is independently associated with neurodevelopmental dysfunction one year after surgery [11,35].

To our knowledge, this is the first systematic review looking at surgical outcomes after repair of ToF in syndromic patients. Methodological strengths of the present paper include (1) comprehensive literature search following rigorous and systematic methodology, (2) detailed data extraction with pre-piloted forms, and (3) standardized quality assessment of eligible studies using the Newcastle-Ottawa Quality scale. This analysis has certain limitations. First, as with any systematic review, certain studies did not report on all outcomes of interest and therefore relative rates were estimated based on available data. Clinical manifestations were only reported in two papers $[7,13]$. Second, eligible studies did not consistently report whether residual RVOT obstruction, chronic pulmonary regurgitation, and surgical or transcatheter pulmonary valve replacement occurred. Therefore, we could not estimate the true incidence of these important complications in syndromic patients undergoing surgical repair of ToF. Similarly, we could not assess whether placing a mechanical prosthetic valve in the RVOT at the time of transannular patch affects the postoperative course or severity of pulmonary insufficiency.

\section{Conclusion}

Syndromic Tetralogy of Fallot accounts for approximately $15 \%$ of all ToF cases. Deletion of 22q11.2 and Down syndrome are the most prevalent genetic abnormalities associated with ToF. Aortic dilatation and MAPCAs constitute the most common forms of comorbid cardiac pathology. Nearly $25 \%$ of patients with syndromic ToF undergo some type of palliation prior to complete intracardiac repair, which may be associated with the high rate of hypoplastic pulmonary arteries that is seen in this patient population. Although relief of RVOT obstruction is typically performed with transannular patch placement, pulmonary valve-sparing technique or RV-PA conduits are used in over one-third of syndromic patients. Long-term survival exceeds $90 \%$, suggesting that surgical management should be dictated by anatomy regardless of genetics.

\section{Compliance with Ethical Standards}

Conflict of interest The authors declare that they have no conflict of interest.

Research Involving Human Participants and/or Animals This article does not contain any studies with human or animal participants performed by any of the authors.

Informed Consent This article does not require informed consent 


\section{References}

1. Villafañe J, Feinstein JA, Jenkins KJ, Vincent RN, Walsh EP, Dubin AM, Geva T, Towbin JA, Cohen MS, Fraser C, Dearani J, Rosenthal D, Kaufman B, Graham TP Jr., Adult Congenital and Pediatric Cardiology Section, American College of Cardiology (2013) Hot topics in tetralogy of Fallot. J Am Coll Cardiol 62(23):2155-2166. https://doi.org/10.1016/j.jacc.2013.07.100

2. Bailliard F, Anderson RH (2009) Tetralogy of Fallot. Orphanet J Rare Dis 4(1):2-137. https://doi.org/10.1186/1750-1172-4-2

3. Michielon G, Marino B, Formigari R, Gargiulo G, Picchio F, Digilio MC, Anaclerio S, Oricchio G, Sanders SP, Donato RM (2006) Genetic syndromes and outcome after surgical correction of tetralogy of Fallot. Ann Thorac Surg 81(3):968-975. https:// doi.org/10.1016/j.athoracsur.2005.09.033

4. Anaclerio S, Di Ciommo V, Michielon G, Digilio MC, Formigari R, Picchio FM, Gargiulo G, Di Donato R, De Ioris MA, Marino B (2004) Conotruncal heart defects: impact of genetic syndromes on immediate operative mortality. Ital Heart J 5(8):624-628

5. Wells GA, Shea B, O'Connell D, Peterson J, Welch V, Losos M, et al. The Newcastle-Ottawa Scale (NOS) for assessing the quality of nonrandomised studies in meta-analyses. https://www.ohri. ca/programs/clinical_epidemiology/oxford.asp. Accessed 25 Apr 2016

6. McDonald R, Dodgen A, Goyal S, Gossett JM, Shinkawa T, Uppu SC, Blanco C, Garcia X, Bhutta AT, Imamura M, Gupta P (2013) Impact of 22q.112 deletion on the postoperative course of children after cardiac surgery. Pediatr Cardiol 34(2):341-347. https://doi. org/10.1007/s00246-012-0454-x

7. Ziolkowska L, Kawalec W, Turska-Kmiec A, Krajewska-Walasek M, Brzezinska-Rajszys G, Daszkowska J, Maruszewski B, Burczynski P (2008) Chromosome 22q.112 microdeletion in children with conotruncal heart defects : frequency, associated cardiovascular anomalies, and outcome following cardiac surgery. Eur J Pediatr 167(10):1135-1140. https://doi.org/10.1007/s0043 1-007-0645-2

8. Fudge JC Jr, Li S, Jaggers J, O’Brien SM, Peterson ED, Jacobs JP, Welke KF, Jacobs ML, Li JS, Pasquali SK (2010) Congenital heart surgery outcomes in Down syndrome: analysis of a national clinical database. Pediatrics 126(2):315-322. https://doi.org/10.1542/ peds.2009-3245

9. Atallah J, Joffe AR, Robertson CM, Leonard N, Blakley PM, Nettel-Aguirre A, Sauve RS, Ross DB, Rebeyka IMWestern Canadian Complex Pediatric Therapies Project Follow-up Group (2007) Two-year general and neurodevelopmental outcome after neonatal complex cardiac surgery in patients with deletion 22q.112: a comparative study. J Thorac Cardiovasc Surg 134(3):772-777. https://doi.org/10.1016/j.jtcvs.2007.03.007

10. Chowdhury UK, Mishra AK, Balakrishnan P, Sharma S, Kabra M, Ray R, Kalaivani M, Gupta R, Govindappa RM, Subramaniam GK (2008) Role of fibrillin-1 genetic mutations and polymorphism in aortic dilatation in patients undergoing intracardiac repair of tetralogy of Fallot. J Thorac Cardiovasc Surg 136(3):757-766. https://doi.org/10.1016/j.jtcvs.2007.12.044

11. Zeltser I, Jarvik GP, Bernbaum J, Wernovsky G, Nord AS, Gerdes M, Zackai E, Clancy R, Nicolson SC, Spray TL, Gaynor JW (2008) Genetic factors are important determinants of neurodevelopmental outcome after repair of tetralogy of Fallot. J Thorac Cardiovasc Surg 135(1):91-97. https://doi.org/10.1016/j.jtcvs 2007.04.074

12. Kyburz A, Bauersfeld U, Schinzel A, Riegel M, Hug M, Tomaske M, Valsangiacomo Büchel ER (2008) The fate of children with microdeletion 22q.112 syndrome and congenital heart defect: clinical course and cardiac outcome. Pediatr Cardiol 29(1):76-83. https://doi.org/10.1007/s00246-007-9074-2
13. Mercer-Rosa L, Pinto N, Yang W, Tanel R, Goldmuntz E (2013) 22q.112 Deletion syndrome is associated with perioperative outcome in tetralogy of Fallot. J Thorac Cardiovasc Surg 146(4):868873. https://doi.org/10.1016/j.jtcvs.2012.12.028

14. Song MS, Hu A, Dyamenahalli U, Chitayat D, Winsor EJ, Ryan G, Smallhorn J, Barrett J, Yoo SJ, Hornberger LK (2009) Extracardiac lesions and chromosomal abnormalities associated with major fetal heart defects: comparison of intrauterine, postnatal and postmortem diagnoses. Ultrasound Obstet Gynecol 33(5):552559. https://doi.org/10.1002/uog.6309

15. Repetto GM, Guzmán ML, Delgado I, Loyola H, Palomares M, Lay-Son G, Vial C, Benavides F, Espinoza K, Alvarez P (2014) Case fatality rate and associated factors in patients with $22 \mathrm{q} 11$ microdeletion syndrome: a retrospective cohort study. BMJ Open 4(11):e005041. https://doi.org/10.1136/bmjopen-2014-005041

16. Rauch R, Hofbeck M, Zweier C, Koch A, Zink S, Trautmann U, Hoyer J, Kaulitz R, Singer H, Rauch A (2010) Comprehensive genotype-phenotype analysis in 230 patients with tetralogy of Fallot. J Med Genet 47(5):321-331. https://doi.org/10.1136/ jmg.2009.070391

17. Chessa M, Butera G, Bonhoeffer P, Iserin L, Kachaner J, Lyonnet S, Munnich A, Sidi D, Bonnet D (1998) Relation of genotype 22q11 deletion to phenotype of pulmonary vessels in tetralogy of Fallot and pulmonary atresia-ventricular septal defect. Heart 79(2):186-190

18. Momma K, Kondo C, Ando M, Matsuoka R, Takao A (1995) Tetralogy of Fallot associated with chromosome 22q11 deletion. Am J Cardiol 76(8):618-621. https://doi.org/10.1016/S0002 -9149(99)80170-2

19. Momma K, Kondo C, Matsuoka R (1996) Tetralogy of Fallot with pulmonary atresia associated with chromosome 22qll deletion. $\mathrm{J}$ Am Coll Cardiol 27(1):198-202. https://doi.org/10.1016/07351097(95)00415-7

20. Wyse RK, al-Mahdawi S, Burn J, Blake K, (1993) Congenital heart disease in CHARGE association. Pediatr Cardiol 14(2):7581. https://doi.org/10.1007/BF00796983

21. Al Habib HF, Jacobs JP, Mavroudis C, Tchervenkov CI, O'Brien SM, Mohammadi S, Jacobs ML (2010) Contemporary patterns of management of tetralogy of Fallot: data from the Society of Thoracic Surgeons Database. Ann Thorac Surg 90(3):813-820. https://doi.org/10.1016/j.athoracsur.2010.03.110

22. Leonardi B, Secinaro A, Calvieri C, Perrone MA, Gimigliano F, Muscogiuri G, Carotti A, Drago F (2019) The role of 3D imaging in the follow-up of patients with repaired tetralogy of Fallot. Eur Rev Med Pharmacol Sci 23(4):1698-1709. https://doi. org/10.26355/eurrev_201902_17132

23. Yang S, Wen L, Tao S, Gu J, Han J, Yao J, Wang J (2019) Impact of timing on in-patient outcomes of complete repair of tetralogy of Fallot in infancy : an analysis of the United States National Inpatient 2005-2011 database. BMC Cardiovasc Disord 19(1):46. https://doi.org/10.1186/s12872-019-0999-1

24. Menaissy Y, Omar I, Mofreh B, Alassal M (2019) Total correction of tetralogy of fallot in the first 60 days of life in symptomatic infants : is it the gold standard ? Thorac Cardiovasc Surg https:// doi.org/10.1055/s-0039-1678698

25. Woldu KL, Arya B, Bacha EA, Williams IA (2014) Impact of neonatal versus nonneonatal total repair of tetralogy of fallot on growth in the first year of life. Ann Thorac Surg 98(4):1399-1404. https://doi.org/10.1016/j.athoracsur.2014.05.034

26. Gladman G, McCrindle BW, Williams WG, Freedom RM, Benson LN (1997) The modified Blalock-Taussig shunt: clinical impact and morbidity in Fallot's tetralogy in the current era. J Thorac Cardiovasc Surg 114(1):25-30. https://doi.org/10.1016/S0022 -5223(97)70113-2

27. Vohra HA, Adamson L, Haw MP (2008) Is early primary repair for correction of tetralogy of Fallot comparable to surgery after 6 
months of age? Interact Cardiovasc Thorac Surg 7(4):698-701. https://doi.org/10.1510/icvts.2008.180083

28. Neirotti R, Galindez E, Kreutzer G, Rodriguez Coronel A, Pedrini M, Becu L (1978) Tetralogy of Fallot with subpulmonary ventricular septal defect. Ann Thorac Surg 25(1):51-56. https://doi. org/10.1016/j.jtcvs.2014.11.087

29. Hemmati P, Dearani JA, Daly RC, King KS, Ammash NM, Cetta F, Schaff HV (2018) Early outcomes of cardiac surgery in patients with noonan syndrome. Semin Thorac Cardiovasc Surg S1043-0679(18):30374-30375. https://doi.org/10.1053/j.semtc vs.2018.12.004

30. Sarris GE, Comas JV, Tobota Z, Maruszewski B (2012) Results of reparative surgery for tetralogy of Fallot: data from the European Association for Cardio-Thoracic Surgery Congenital Database. Eur J Cardiothorac Surg 42(5):766-774. https://doi.org/10.1093/ ejcts/ezs478

31. Karamlou T, McCrindle BW, Williams WG (2006) Surgery insight: late complications following repair of tetralogy of Fallot and related surgical strategies for management. Nat Clin Pract Cardiovasc Med 3(11):612-622. https://doi.org/10.1038/ncpca rdio0682

32. Stewart RD, Backer CL, Young L, Mavroudis C (2005) Tetralogy of Fallot: results of a pulmonary valve-sparing strategy. Ann
Thorac Surg 80(4):1431-1439. https://doi.org/10.1016/j.athor acsur.2005.04.016

33. Stellin G, Jonas RA, Goh TH, Brawn WJ, Venables AW, Mee RB (1983) Surgical treatment of absent pulmonary valve syndrome in infants: relief of bronchial obstruction. Ann Thorac Surg 36(4):468-475. https://doi.org/10.1016/S0003-4975(10)60491-2

34. Ilbawi MN, Fedorchik J, Muster AJ, Idriss FS, DeLeon SY, Gidding SS, Paul MH (1986) Surgical approach to severely symptomatic newborn infants with tetralogy of Fallot and absent pulmonary valve. J Thorac Cardiovasc Surg 91(4):584-589

35. Maharasingam M, Ostman-Smith I, Pike MG (2003) A cohort study of neurodevelopmental outcome in children with DiGeorge syndrome following cardiac surgery. Arch Dis Child 88(1):61-64. https://doi.org/10.1136/adc.88.1.61

Publisher's Note Springer Nature remains neutral with regard to jurisdictional claims in published maps and institutional affiliations. 